\title{
O HAICAI NO BRASIL - ASSIMILAÇÃO OU UMA NOVA REALIZAÇÃO POÉTICA?
}

Sonia Regina Longhi Ninomiya

\section{Introdução}

Certamente, é do conhecimento de todos os excelentes estudos do professor e haicaísta Paulo Franchetti, da Unicamp, sobre o haicai, enquanto forma poética japonesa e enquanto forma poética praticada no Brasil. Portanto, não me aterei a considerações sobre as circunstâncias, o processo da introdução desta forma poética e sua prática no nosso país.

Apesar do título pretensioso que dei a este artigo, gostaria, na verdade, de, restringindo o foco de Brasil para Niterói, no Rio de Janeiro, falar de um haicaísta específico e de sua visão sobre esta poesia para discorrer sobre o meu tema.

Inicialmente, gostaria de apresentar algumas definições de haicai cunhadas em língua portuguesa desde há muito.

Como nos aponta Franchetti (1990), "uma das primeiras definições de haikai no Ocidente foi escrita em português:

Há hua sorte de versos a modo de Renga que chama: Faicai, de estillo mais baixo $\&$ o verso he de palavras ordinárias, ..."

Essas são palavras do Pe. João Rodrigues que constam da Arte da lingoa de Iapan, de 1604 .

1. HAIKAI. Paulo Franchetti, Elza Taeko Doi e Luiz Dantas, São Paulo:UNICAMP, 1990; p.37. 
Mais um português nos deu informação sobre o haicai, cerca de 300 anos depois. Trata-se de Wenceslau de Moraes (1908), que escreveu em uma de suas cartas publicada no jornal $O$ Comércio do Porto:

... a uta de nossos dias (...) é ainda o murmúrio espontâneo, quase inconsciente, que o japonês solta, como o rouxinol, como a rã, para traduzir o seu sentimento, de desejos, de alegria, de mágoas ou de dor. (...) a uta participa da mesma inconsistência, da mesma fluidez, da mesma parcimónia de detalhes (da pintura japonesa). Como a pintura, é mais do que tudo um estimulo das nossas recordações, do que vimos, do que sentimos, do que sofremos. (...) Reduzido em geral cada poema a dimensões infimas, não excedendo ordinariamente trinta e uma sílabas, contendo às vezes apenas dezassete, a habilidade do poeta consiste em agrupar dentro destes curtos limites uma suficiente escolha de palavras, que sugiram uma profunda impressão íntima. ${ }^{2}$

Embora, nessa definição, Moraes não faça distinção entre waka e haikai, chamando a ambos de uta, ele pontua a parcimônia de detalhes e a apreensão da poesia japonesa enquanto "estímulo" de nossa vivência. Já não é mais o haicai apenas um poema de "estilo mais baixo", "de palavras ordinárias". Já se trata de um fazer poético com status de literatura.

Muitos foram os brasileiros que trataram do haicai, desde Osório Dutra em 1920, com sua caracterização preconceituosa do gênero, passando pela expressão parnasiana de Guilherme de Almeida, do concretismo de Haroldo de Campos, a reinterpretação de Paulo Leminski, dentre outros. Mas, o tema desta comunicação, não é ligado aos nomes de projeção no cenário literário, senão aos que de fala portuguesa conheceram, apreenderam, compuseram e semearam o haicai, em língua portuguesa, no Brasil. E há uma intensa atividade de haicaístas compondo em língua portuguesa ligados a grupos vários, sendo um dos mais conhecidos o do Grêmio Haicai Ipê.

O "estimulo" da definição de Moraes , pode ser bem completado com a colocação de Franchetti:

(...) o registro ou o despertar de uma percepção muito ampla ou intensa nascida de uma sensação. Esse me parece o núcleo da forma do haicai. ${ }^{3}$

E eis que essa "percepção muito ampla ou intensa", esse "estímulo" se materializa em um haicai para definir o próprio haicai :

2. ANTOLOGIA, Wenceslau de Moraes. Organização, seleção de textos e introdução de Armando Martins Janeira, Coleção Mnésis - Clássicos da Literatura Portuguesa, Vega, Lisboa, 1993, 2ª .edição, p.227-228.

3. OESTE. Paulo Franchetti, São Paulo, 2008, prefácio. 


\section{Que é um haicai?}

É o cintilar das estrelas

Num pingo de orvalho. ${ }^{4}$

Quem assim define esse gênero poético é Luís Antonio Pimentel, cuja poesia, principalmente os haicais serão o tema desta fala.

\section{O homem e o poeta}

Luís Antonio Pimentel nasceu em Miracema, Rio de Janeiro, em 1912, mas desde os dois anos de idade passou a viver em Niterói, Rio de Janeiro. Órão de pai aos três anos de idade, já aos dezessete começou a trabalhar em jornal, atividade que exerce até os dias de hoje, tendo passado por vários jornais conceituados, tanto em Niterói quanto na cidade do Rio de Janeiro. A partir de 1933, integrou-se ao corpo de jornalistas dA Nação, onde trabalhou ao lado de Cecília Meirelles, de seu esposo Corrêa Dias, de Carlos Lacerda, dentre outros. Mais tarde foi para a Gazeta de Notícias, onde ficou até 1937, quando embarcou para o Japão.

Inicialmente estudou na Escola Nacional de Belas Artes, até sua seleção para estudar no Japão e depois de seu retorno, reingressou na universidade, diplomando-se, em 1952, em jornalismo pela Faculdade Nacional de Filosofia da Universidade do Brasil, hoje Universidade Federal do Rio de Janeiro.

Escolhido pelo então Reitor da Universidade do Brasil, Sr. Prof. Raul Leitão da Cunha, para usufruir da bolsa de estudos oferecida pelo Instituto Cultural Nippo-Brasileiro e pelo Governo japonês, Pimentel estudou no Japão, mais precisamente no Waseda Kokusai Gakuin da Universidade de Waseda, língua e cultura japonesa, de 1937 a 1939. Finda sua bolsa de estudos, optou por permanecer no Japão, desta feita trabalhando na Rádio de Tóquio, onde era locutor em língua portuguesa. Trabalhou, também, esporadicamente, no Consulado brasileiro em Tóquio.

A história parece ter interferido em seus planos e em 1942, em plena guerra do Pacífico, teve que deixar o Japão, fazendo-o no último navio de evacuação de estrangeiros, o Tatsuta Maru. Em Lourenço Marques, hoje Maputo, capital de Moçambique, colônia de Portugal, à época país neutro, operou-se a troca dos evacuados do Japão pelos japoneses vindos das Américas. Assim, a bordo do navio de bandeira sueca, o Grips Holm, Pimentel retorna ao Rio de Janeiro. Permaneceu ao todo cinco anos e dois meses no Japão.

4. TANKAS E HAICAIS in Prosa e Poesia Reunidas, Obras Reunidas 2, Luis Antonio Pimentel; Organização e Notas Aníbal Bragança, Niterói Livros, Niterói, 2004, p.256 
Como se pode ver, trata-se de um senpai de muitos de nós, brasileiros que estudamos no Japão. Luís Antonio Pimentel, jornalista, poeta, escritor, memorialista, pesquisador do folclore brasileiro, fotógrafo, artista plástico e compositor bissexto. É mesmo um verbete da Enciclopédia Delta-Larousse.

Pimentel publicou seu primeiro livro de poesias em 1933, Ciranda, cirandinha... e se apresentava, aos 21 anos de idade como o "rapaz desiludido que passava" e que ao fim da 'brincadeira da ciranda, cirandinha' foi o "único que ficou sem par" Nesse seu primeiro livro, ele descreve, no poema que lhe dá título, a alma do poeta como sendo "uma janela escancarada para a beleza universal..." e é esse escancaramento que possibilita a Pimentel apreender o Japão e a poesia japonesa.

No Japão daquela época, ele privou da companhia de grandes nomes da literatura e das artes japonesas, como Kawabata, Horiguchi Daigaku, Tange Murata, dentre outros, dos quais tem viva recordação. Conheceu, também, Ôtake Wasaburo, com quem dialogou algumas vezes sobre o sentido de vocábulos em português. Segundo Pimentel, foi com Horiguchi Daigaku que penetrou nos segredos do haicai.

Contou, também, com a amizade e a assessoria lingüística de Yonekura Teruo. Yonekura viveu no Brasil e estudou em escola brasileira o que o fez conhecedor da língua portuguesa e era, também, poeta. A sensibilidade que uniu essas duas criaturas fortaleceu uma grande amizade que frutificou na tradução para o japonês dos poemas de Pimentel. E assim nasceu Namida no kitô (Prece em lágrimas - inédito em português), publicado em 1940, em Tóquio, pela editora Daichi. Nesse livro há um poema que, segundo Pimentel, causou certa perplexidade nos literatos japoneses que o ouviram, em certo sarau, pelo ineditismo do tratamento dado ao monte Fuji pelo nosso poeta. Trata-se de

O Fuji dentro da tarde

$\mathrm{Na}$ tarde sonolenta

O Fuji-san se erguia,

por entre o quimono macio das nuvens,

impávido como um seio virgem,

para receber os últimos beijos

do Sol ardente que morria...

夕暮富士

静かな たそがれ 


\section{白雲の衣を押しわけ \\ 乙女の乳房を思わせて \\ 優しく富士がそびえたつ \\ あかあかと沈む 日輪に \\ 最後の接吻を求めながら}

Seu editor no Japão, à época, Shiratori Shogo, considera que os versos de Pimentel têm a "paixão sulista", cujo sentimento "brota incontido". E, ainda, no prefácio de Namida no kitô (Prece em lágrimas), nos diz acolhedor:

A arte não tem fronteiras. Quando o sr. Pimentel, sentado na mesa ao lado, olhar inocente e brilhante, declama seus poemas repletos de sentimento, nos esquecemos de nossas nacionalidades. Reside ai o respeito artístico. ${ }^{5}$

Embora tenha me proposto a falar do haicai de Pimentel, não pude deixar de mencionar esse seu poema, pois é um dos que mais lhe agradam e lembram o Japão.

Seria, ainda, interessante considerar que Namida no kitô, uma coletânea de 115 poemas, tem os originais em língua portuguesa desaparecidos. Lendo-os em japonês, tornase dificil perceber que foram escritos por um brasileiro. Contudo, é verdade que o lirismo de Pimentel é mais ardente do que aquele brota da pena dos poetas japoneses, pois é colorido pelo sensualismo, talvez o mesmo veio que vai aflorar em alguns de seus haicais. Mas, a temática de seus poemas deixa transparecer o quanto já havia assimilado do modus vivendi japonês, da simbologia de seus mitos.

Pimentel nos fala da amada e de algumas tradições culturais que já não são nem a figura feminina nem as idiossincrasias culturais apercebidas pelo filtro do exotismo do início do século XIX, mas sim pelo livre trânsito e pelo conhecimento dos matizes do momento histórico-social do Japão da época. Nesse sentido, é rica sua contribuição para que conheçamos um pouco do Japão que não encontramos nos livros. Em seu poema Sen'ninbari, ele retrata o costume originado na guerra sino-japonesa de $1894 \mathrm{de}$, em um pedaço de tecido branco, mil mulheres darem mil pontos rococó. Esse tecido era levado pelos soldados, que partiam para a linha de frente, no bolso ou no peito, como um amuleto que lhes permitiria retornar à pátria em segurança. O sen'ninbari era fruto da perseverança de mulheres, mães e esposas, para proteger seus entes queridos dos perigos inevitáveis. A sensibilidade de Pimentel ao captar o momento dá conta do orgulho e da devoção do afã dessas mulheres. O momento era o da nova

5. Ibidem, p.220. 
investida japonesa contra a China, em 1937, quando esse costume fora retomado e vivenciado por Pimentel. O poeta, então, nos fala de todas as mãos a lhe encher os olhos democráticos, e o tom é realmente lastimoso. As mãos delgadas da enfermeira, as mãos refinadas da senhorinha, as mãos pecaminosas da gueixa, as mãos ágeis e graciosas das dançarinas, as mãos grosseiras das proletárias, todas essas mãos imbuídas de um só espírito patriótico transferem-no para o tecido, como que a cozer as veias dos bravos soldados antes mesmo de se terem rompido.

No poema Chôchin Gyoretsu (Parada de lanternas), também aparece a temática da guerra. Todas as lanternas que parecem corações inflamados e todos os corações que parecem lanternas acesas, bandeirolas agitadas e a multidão, como que em onda, passam pela cidade. Toda a cena é acompanhada pelos olhos úmidos da jovem viúva, recolhida à sombra da multidão. A percepção do drama pessoal nos chega sugerida, bem ao estilo japonês de representação da dramática realidade. Ao ler o poema não pude evitar a recordação do conto Hankechi (O lenço) de Akutagawa Ryunosuke, escrito em 1916, que retrata uma mãe participando ao professor a morte de seu filho e agradecendo toda a atenção que lhe dedicara em vida. A aparente tranqüilidade da mãe não deixava transparecer seu drama que, no entanto, se mostrava no torcer do lenço sob a mesa, enquanto conversava com o professor. Essa sutileza na apreensão do drama me sabe uma influência japonesa na expressão poética de Pimentel.

Quando o poeta trata do amor, da mulher amada, nessa coletânea, seu sangue latino está presente, como bem o diz Shogo, mas o sensualismo é sutil. Sua amada é japonesa e sua falta é chorada como o despetalar das flores das cerejeiras ao sabor da brisa, como em Soyokaze.

\section{Pimentel e o haicai}

Em 1953, Pimentel publicou Tankas e Haicais ${ }^{6}$. Aos seus tankas, apensa um título, como se a contextualizar o poema. A temática é indígena ao Brasil e a "paixão sulista" também se faz presente. Vejamos:

\section{Lirismo}

$\mathrm{Na}$ haste branca e nervosa

do teu corpo esguio de repuxo,

colhi a flor rubra do teu beijo.

\section{Tristeza}

Quando chove lá no morro,

6. Ibidem, p.237-267. 
sem as bandeiras das roupas, as cordas ficam chorando.

O próprio Pimentel, no Posfácio de Tankas e Haicais, diz que a poesia japonesa é de "transplantação difícil para o nosso idioma, por falta de clima lingüístico" e que somos prolixos demais para poetarmos quer seja em 31 ou 17 sílabas. Mas que lhe é irresistivel compor os seus.

Pimentel compara o tanka ao nosso epigrama, na forma e, quanto ao conteúdo, assinala a delicadeza e a emoção da sua essência.

Nesses dois tankas citados, não encontramos o esquema da "versificação" em um terceto de 5-7-5 sílabas e um dístico de 7-7 sílabas. Nem a relação típica entre o terceto e o dístico, que a rigor não deve ter um nexo lógico. Mas podemos apreender, no primeiro exemplo - Lirismo um comentário sobre os dois primeiros versos. De repente o beijo roubado que deixara a donzela miúda (indefesa?) encabulada. No segundo exemplo - Tristeza - embora a relação entre as partes me pareça um tanto explicativa, o sentimento de tristeza se mantêm por todas as estrofes - quando a chuva impede até mesmo a exposição das bandeiras, às cordas só restam as lágrimas.

Os haicais de Pimentel, são mais "canônicos" quanto à metrificação, mas nem sempre há a preocupação com o "kigo" Ele próprio nos confessa que não a acha imprescindível. Porém, sabe usá-la com maestria:

O campo é um mar...

nos trigais em ondas de ouro, mergulham pardais.

\author{
Pesados de cana, \\ rangem os carros-de-boi \\ moendo as estradas...
}

Está-se falando do outono, época de colheita da cana, do trigo. O carro de boi deixa sua marca na estrada poeirenta e os pardais aproveitam a última oportunidade de conseguir o alimento farto e fácil. Esses instantâneos do momento vivido são retratados de forma direta, simples e leve.

Vejamos o que Pimentel tem a nos dizer sobre a poesia japonesa:

Recebendo sempre por poema o que para nós seria apenas um tema, os japoneses se tornaram poetas para poder sentir sua própria poesia. Em realidade, onde poderemos nós encontrar a beleza se não a tivermos dentro de nós mesmos?7

Percebemos, então que o nosso poeta liga o haicai ao sentir daquilo que é poético e

7. Ibdem, p. 266 . 
que a beleza do poético é bela pois reside dentro de nós. É, então, com o belo que trazemos em nós que clareamos a percepção que vem de uma sensação intensa como nos coloca Franchetti. Certamente é com essa "beleza" que, vendo a realidade, dela nos distanciamos, retratando com simplicidade a apreensão do instante. Vejamos esses haicais

$$
\begin{aligned}
& \text { Nos beirais em festa, } \\
& \text { em ninhos feitos de lama, } \\
& \text { trissam andorinhas. }
\end{aligned}
$$

Pitangueira nova,

Cheia de frutos maduros

- festa de lanternas.

A visão das andorinhas trissando no ninho tosco ou dos frutos maduros da pitangueira é posta em palavras enquanto descrição daquela verdade apreendida pela sensibilidade e nos toca pelo ar festivo que contem em si. No meu modesto entendimento desse gênero poético japonês, isso é haicai. Nos fala de uma sensação atemporal, que realmente não tem fronteiras, nem fisicas nem lingüísticas.

Mas Pimentel é brasileiro e, como bem diz Wenceslau de Moraes "não se pode enjeitar heranças ancestrais, de tendências, de preferências, legadas durante inúmeros séculos, por uma infinidade de ascendentes, muito embora os caprichos do destino nos arremessem aos antípodas" ${ }^{8}$ Nesse sentido, alguns haicais de Pimentel não são mais assimilação, mas sim uma nova realização poética à maneira de haicai.

Sua definição de haicai é um bom exemplo. A indagação "Que é um haicai?" mesmo sendo uma pergunta retórica, é algo estranho ao gênero poético em questão - algo da ordem da argumentatividade ocidental, talvez - mas que Pimentel experiencia enquanto haicaísta brasileiro para poder se explicar. E seu explicar é precioso, apaixonado, mas talvez distante da "leveza" creditada a esse gênero poético. Por outro lado, sua explicação pode estar significando aquilo que não foi explicitado em palavras, mas está contido no sentido. Afinal, o haicai é um poema curtíssimo, mas que diz muito e no "pingo de orvalho" está contido "o cintilar das estrelas"

Pimentel tem haicais que me remetem a Kobayashi Issa:

$$
\begin{aligned}
& \text { Pesados de cana, } \\
& \text { rangem os carros de boi } \\
& \text { moendo as estradas. }
\end{aligned}
$$

8. Moraes, W. Op.cit., p. 109 
Nas mãos da criança,

a pombinha de papel

arrulha e até fala.

Pé no meio-fio,

pé na vala, vai feliz

o menino coxo.

Outros trazem a marca do "eu lírico" do poeta, da estética do romantismo, do simbolismo. $\mathrm{O}$ amor, tema alheio ao haicai, aparece sutilmente cantado nos versos do nosso poeta, mas nos faz perceber as muitas nuanças do não expresso, mas sugerido.

Fitando um retrato,

Seus olhos eram hortênsias

lindas, aljofradas.

Teus lábios sem par, refletidos na vitrine, eram jóia rara.

Na aléia cheirosa, o ramo que me feriu cobriu-a de flores

Lágrimas no cais.

Um lenço sonha ser vela...

poder navegar.

$\mathrm{Na}$ entrevista que deu a Kahlmeyer-Mertens', quando perguntado sobre se os símbolos, as figuras de linguagem, o subjetivismo observado em sua poesia seriam características próprias ou traços do haicai, Pimentel pontuou com maestria o que transpondo a assimilação resultou em uma nova realização poética, denunciadora da individualidade que já sabe lidar com as "heranças ancestrais" e os "caprichos do destino" Vamos ouvir o próprio Pimentel:

Alguns destes simbolos estão muito ligados ao sentimento búdico, outros são transgressões mesmo. De certo modo, essas já se vêem na poesia do Issa. Ele se

9. Roberto Saraiva Kahlmeyer-Mertens, Verdade-metafísica-poesia - Um ensaio de filosofia a partir dos haicais de Luís Antonio Pimentel, Niterói, RJ, Nitpress, 2007. 
distancia da poesia de Bashô como também venho me rebelando. Veja só, introduzi o haicai onomástico, que Bashô não faria; o haicai erótico, que está fora do cânon de Bashô; o haicai engajado, panfletário, que Bashô não faria, pois para ele o haicai tem que se referir aos fenômenos da natureza e das suas coisas belas $e$ suaves, nunca às coisas penosas e tristes. (p.52)

E, perguntado sobre seu processo de criação, ele diz:

Não há nada de especial. A poesia vem, vejo se ela cabe no metrón e boto no papel. (...) O haicai não é obra de lapidário, é obra para quem tem atenção de colher o instante. (p.72)

Não poderia concluir esse artigo sem mencionar alguns dos haicais "transgressores" de Pimentel. Eis alguns, apenas para sentir o sabor dessa transgressão, dos onomásticos aos engajados:
Maria, irmã leiga,
pérola da Boa Viagem,
é guardiã da ilha.

Em teus olhos, verde,

em tua boa, vermelho.

Paro, ou continuo?

Da língua em três saltos, pelo céu da boca nasce teu nome: Lo-li-ta.

Decorei teu corpo.

Sei-o, na ponta da língua, melhor que ninguém.

Cafezal maduro.

Gotas de sangue de escravos

brotando em rubis.

Dia sobre a noite.

Do ventre inflado da negra

fulgura a mulata.

Cultive-a sem terra,

a gleba é sua também.

Deus a fez para todos. 
Com invejável vitalidade, o haicaísta transgressor Luís Antonio Pimentel completou 96 anos em 29 de março deste ano e continua a exercer suas atividades jornalísticas, a poetar e a falar do Japão, lá em Niterói. 